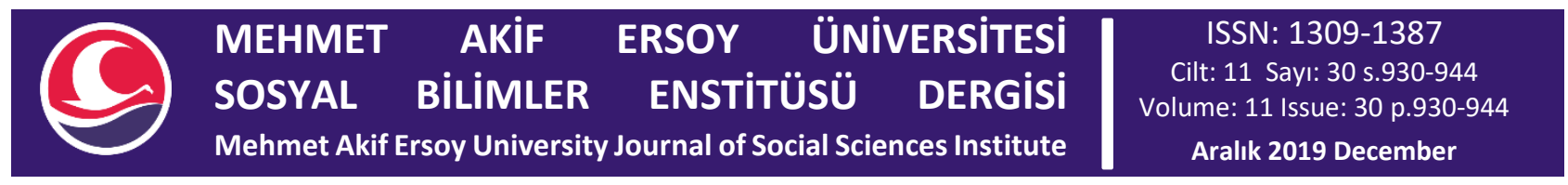

\title{
FİRMA DEĞERLEME YAKLAŞIMLARI VE TÜRK HAVA YOLLARI (THY) ÜZERINE BİR UYGULAMA
}

\section{FIRM VALUATION APPROACHES AND AN APPLICATION ON TURKISH AIRLINES (THY)}

Yüksel Akay ÜNVAN ${ }^{1}$

1. Doç. Dr., Ankara Yıldırım Beyazıt Üniversitesi, İşletme Fakültesi, Bankacıllk ve Finans Ana Bilim Dalı, Türkiye, akay.unvan@gmail.com, https://orcid.org/0000-0002-0983-1455

\begin{tabular}{|rr}
$\begin{array}{l}\text { Makale Türü } \\
\text { Araştırma Makalesi }\end{array}$ & $\begin{array}{r}\text { Article Type } \\
\text { Research Article }\end{array}$ \\
Başvuru Tarihi & Application Date \\
30.10 .2019 & 10.30 .2019 \\
& \\
Yayına Kabul Tarihi & Admission Date \\
20.11 .2019 & 11.20 .2019
\end{tabular}

DOI

10.20875/makusobed.640267 $\ddot{\text { Öz }}$

Bu çalışma kapsamında, rekabet koşullarının her geçen gün zorlaştığı küresel finans pazarında önemini giderek daha da arttıran firma değerleme kavramı ele alınarak, öncelikle konuyu işleyen çeşitli çalışmaların derlendiği bir literatür taraması yapılmış, ardından havayolu ulaşımı sektöründe faaliyet gösteren Türk Hava Yolları șirketi için bir firma değerleme uygulaması anlatılmıştır. Söz konusu değerleme için yöntem olarak indirgenmiş serbest nakit akım ve benzer şirket yöntemleri kullanılmış ve elde edilen sonuçlar tutarlılık açısından kıyaslanmıştır. Değerleme hatasının minimum düzeyde tutulması ve hissenin gerçeğe yakın değerine ulaşılması için, değerlemede mümkün olduğunca çok yöntemin karşılaştırmalı olarak kullanılması önerilmektedir. Ayrıca, sağlıklı bir değerleme sonucu elde edebilmek için, değerlemede kullanılacak yöntemin seçim ve uygulama sürecinde firmanın ve firmanın faaliyet gösterdiği sektörün spesifik özelliklerinin hassasiyetle dikkate alınması gerektiği de düşünülmektedir.

Anahtar Kelimeler: Firma Değerleme, İndirgenmiş Nakit Akımları Yöntemi, Benzer Firmalar Yöntemi, Türk Hava Yolları,

\section{Abstract}

Within the scope of this study, the concept of firm valuation, which is becoming more and more important in the global financial market where competition conditions are getting difficult increasingly has been examined. For this aim firstly, a literature review has been compiled by various studies dealing with the subject and then a firm valuation application has been applied for the firm Turkish Airlines operating in the airline transportation sector. The reduced free cash flow and similar company methods are used as the method for the valuation and the results are compared for consistency. In order to keep the valuation error minimum and to reach the real value of the stock, it is recommended to use as many methods as possible in the valuation in comparison. In addition, in order to obtain a useful valuation result, it is considered that the specific features of the firm and the sector in which the firm operates should be taken into consideration during the selection and application process of the method to be used in the valuation.

Keywords: Firm Valuation, Reduced Cash Flow Method, Similar Firms Method, Turkish Airlines, 


\section{GíRiș}

Değer kelime anlamı itibariyle bir şeyin önemini belirlemeye yarayan ölçü, yani bir varlığın değdiği karşılık ya da kıymet olarak ifade edilmektedir. Finansal anlamda değer kavramı ise farklı ekonomi düşüncelerine göre farklı tanımlara sahiptir. Neoklasik ekonomi teorilerine göre bir şeyin değeri açık ve rekabetçi bir pazarda getireceği fiyattır. Birçok neoklasik ekonomik teori ise pazarın fiyatı ile değeri eşit kabul eder. Klasik ekonomiye göre ise bir şeyin değeri kullanımı / tüketiminin sağladığı faydadan gelir. Fiyat ile aynı şey değildir (Gorbon, 2012). Finansal anlamda değerleme ise finansal piyasalarda bir varlı̆̆ın piyasa değerinin gerçek değerinden düşük ya da yüksek olup olmadığının belirlenmesine yardımcı olan en temel analizi ifade eder (Aydın, 2012).

$\mathrm{Bu}$ çalışma kapsamında, rekabet koşullarının her geçen gün zorlaştığı küresel finans pazarında, önemini giderek daha da arttıran firma değerleme kavramı ele alınarak, öncelikle konuyu işleyen çalışmaların derlendiği bir literatür taraması verilecek, ardından ise havayolu ulaşımı sektöründe faaliyet gösteren Türk Hava Yolları şirketi özelinde bir firma değerleme uygulaması anlatılacaktır.

\section{LITERATÜR}

Mevcut literatür incelendiğinde farklı firma değerleme yaklaşımlarının hem teorik hem de uygulamalı olarak yer bulduğu görülmektedir. Ayrıca, firma değerleme kavramına etki eden pek çok firma ve sektör spesifik faktörün sürece etkisi de ulusal ve uluslararası pek çok çalışma kapsamında ele alınmıştır. Söz konusu çalışmalardan seçilen bazı özet bilgiler aşağıda paylaşılmıştır.

Hatipoğlu ve Yener (2013) yaptıkları çalışmada indirgenmiş nakit akımları yönteminin enerji sektöründe uygulanabilir sonuçlar verip vermediğini test etmişlerdir. Türkiye ekonomisinde enerji yatırımlarının önemli bir paya sahip olması nedeniyle çalışmada enerji sektörü seçilmiştir. Söz konusu çalışma, nakit akımlarının hem firmaya hem de öz sermayeye göre birlikte analiz edilmesi nedeniyle, literatürdeki diğer çalışmalardan farklılık göstermektedir. Çalışmada ayrıca firma değerlemesi çalışmalarının ve bu çalışmalarda kullanılan yöntemlerin hem subjektif olup hem de çeşitli varsayımlara dayandığı vurgulanarak; analizi yapan kişinin öngörüleri ya da kabul edilen varsayımlar değiştiğinde değerleme çalışmalarının sonuçlarının da değişeceği belirtilmiş ve yatırımcıların her bir değerleme yöntemine göre bulunan sonuçlara belirli bir ağırlıklandırma yaparak bir fiyat aralığına ulaşmaları ve bu fiyat aralığına göre yatırım kararı vermeleri önerilmiştir.

Bilir ve Kulalı (2014), indirgenmiş nakit akımları ve göreceli değerleme yöntemlerinin finansal analistler tarafından çoklukla tercih edildiğini belirterek; indirgenmiş nakit akışı yönteminin amacını, varlığın değerinin, varlığın nakit akışı, büyüme oranı ve riskliliği dikkate alınarak belirlenmesi iken, göreceli değerleme yönteminin amacını ise, varlığın değerinin, piyasadaki benzer varlıkların nasıl fiyatlandığı temelinde ortaya konulması olarak özetlemişlerdir. Çalışmada, belirtilen yöntemlerden hangisinin hangi durumda kullanılmasının daha uygun olacağına karar verilebilmesi amacıyla, araştırmacıları yönlendirecek karşılaştırmalara da yer verilmiştir. Çalışma sonucunda, karşılaştırılan yöntemlerin daha iyi ya da daha kötü olarak sınıflandırılamayacağı; kullanım amacına göre her iki yöntemin de verimli sonuçlar sunduğu vurgulanmıştır. Belirtilen yöntemler arasında yapılacak tercihin ise, yatırım felsefesine, zaman ufkuna ve piyasaya ilişkin kişisel inanışlara bağlı olduğu ortaya koyulmuştur.

Kayalı, Yereli ve Ada (2007) yaptıkları çalışmada, entelektüel sermayenin diğer geleneksel firma değeri tespit kriterleriyle birlikte değerlendirilerek teknoloji firmalarının firma değerlerini etkileyen temel unsurların belirlenmesini amaçlamışlardır. Çalışmada, Ante Pulic'in Entelektüel Katma Değer Katsayısı Yöntemi kullanılarak Türkiye'de BIST'de işlem gören teknoloji firmalarının entelektüel sermayeye verdikleri önem araştırılmıştır. Bu kapsamda yapılan çoklu regresyon ve korelasyon analizleri sonucunda Türkiye'de bilgi yoğun sektörde de dahil olmak üzere entelektüel sermayeye gereken önemin verilmediği vurgusu yapılmıştır.

Alkan ve Demireli (2007) ise global rekabet ortamının piyasa değerini etkilediğini yineleyerek, büyüme stratejilerini belirleme sürecinde birleşme ya da halka arz gibi yöntemleri tercih eden işletmelerin "değerleme" kavramı ile yüz yüze geldiğini ve bu noktada kullanılacak değerleme yöntemi için amaç tespitinin önemini vurgulamışlardır. Seçilecek değerleme yönteminin doğruya en yakın işletme değerini belirlemesi gerektiği ifade edilirken, çalışma kapsamında yapılan örnek bir uygulamada ise, değerleme yöntemlerinden net aktif değer, piyasa değeri, defter değeri, fiyat kazanç oranı, fiyat / nakit akım oranı kullanılarak işletme 
değeri hesaplanmış ve bu yöntemlerin ortalaması alınarak nihai işletme değeri belirlenmiştir. Değerleme yöntemlerinin farklı varsayımlara dayanması, elde edilen sonuçları da farklılaştırdığından; kritik noktanın değerlemenin hangi amaçla yapılacağının dikkate alınması olduğu ifade edilmiştir. Ayrıca, daha etkin bir değerleme süreci için, şirketlerin duran varlıklarına ilişkin amortisman ayırma yöntemlerini doğru belirlemeleri gerektiğinin de altını çizmişlerdir.

Çam (2014) ise politik riskin yatırım kararlarında etkili olmasına atıfla, politik riskin firma değeri üzerinde etkisi olup olmadığına odaklanmıştır. Bu amaçla firma değerinin bu riskten etkilenip etkilenmediği ve etkileniyorsa derecesinin tespit edilmesinin önemine işaret etmiştir. Söz konusu çalışmada, İMKB'ye kayıtlı firmaların firma değeri ile politik risk arasındaki ilişkisi incelenmiş, konuyla ilgili teorik açıklamalara ve literatür incelemesine yer verilmiş, araştırma yöntemi ve veriler tanıtıldıktan sonra ise elde edilen bulgulara ve araştırma sonuçlarına değinilmiş̧ir.

Küçükkocaoğlu'na göre ise firma değerlemede risk faktörünün giderek önem kazanması, daha istikrarsız ve belirsiz bir ekonomik döneme girildiği 1970'li yıllarda gerçekleşmiştir. Risk faktörünün sistemli bir şekilde analizlere dahil edilmesi ise, bilgisayar sistemlerinin dikkate değer bir gelişme göstermesiyle mümkün olmuştur. Modern risk yaklaşımı, ABD'nde sistematize edilmiş ve yaygın bir şekilde kullanılmıştır.

Yusufi Yılmaz, F. (2002) ise öncelikle değer kavramını tanımlayarak firma değerlemenin neden gerekli olduğunu anlatmıştır. Yazar firma değerlemenin karmaşık yapısına vurgu yaparak, firmanın finansal ve organizasyonel yapısı, içinde bulunduğu sektörün niteliği, makroekonomik veriler ve beklentiler ile karşılaştırma amaçlı diğer firmaların değerlerinin sağlıklı bir değerleme için gerekli veriler olduğunu belirtmiştir. Bu kapsamda kullanılan somut verilerin firmaya ait bilançolar ve gelir tabloları olduğuna ve söz konusu finansal verilerin anlamlı olabilmesi için sadece cari durum itibariyle değil geçmiş ve gelecek dönem projeksiyonlarının da analiz edilmesi gereğine işaret edilmiştir. Firma değerlemesinde ilk olarak yurtiçi ve yurtdışı sektör analizi, daha sonra firmanın yapısı ve finansal bilgilerinin incelendiği, elde edilen sonuçlara ve firma koşullarına bağlı olarak kullanılacak değerleme yöntem veya yöntemlerine karar verilmesinin önemi vurgulanmıştır. Çalışmada ayrıca, İndirgenmiş Nakit Akımları Analizi, Piyasa Kriterleri (PD/DD, FK, İşletme Değeri/Kapasite), Tasfiye Değeri/Net Aktif Değer, Ekonomik Katma Değer (EVA®), Yeniden Kurma Maliyeti, İşleyen Teşebbüs Değeri, Ekspertiz Değeri gibi değerleme yöntemleri de belirtilmiştir. Makalenin uygulama bölümünde ise Çimento Sektörü'ne ait Akçansa Çimento Sanayi ve Ticaret A.Ş., Adana Çimento T.A.Ş. ve Batı Anadolu Çimento A.Ş. firmaları için İndirgenmiş Nakit Akımlar, Net Aktif Değer, Ekonomik Katma Değer (EVA) ve Piyasa Kriterlerine göre değerlemeleri yapılmıştır.

Avcı ve Balcı (2017) ise küreselleşme ile birlikte ülkelerarasında ekonomik sınırların ortadan kalktığına dikkat çekerek, rekabet koşullarının zorlaştı̆̆ını ve bu durumun piyasa değerini etkilediğini belirtmişlerdir. Belirtilen koşullarda devamlılıklarını sağlayabilmek ve büyümelerini sürdürmek için firmaların birleşme, devralma, satın alma ve halka arz gibi firma değerlemenin önem kazandığı farklı stratejik yöntemleri kullandıkları ifade edilmiştir. Ayrıca günümüzde kârın maksimizasyonundan ziyade piyasa değerinin maksimizasyonuna odaklanılması gerektiği de vurgulanmıştır. İlgili çalışma kapsamında hem firmaya hem de öz sermayeye göre indirgenmiş nakit akımları yöntemleri ile düzeltilmiş bugünkü değer yöntemleri kullanılarak bir uygulama yapılmış ve elde edilen firma değerleri kıyaslanmıştır.

Masun (2017) ise firma değerlemesi yaklaşımlarını ele aldığı çalışmasında öncelikle bu yaklaşımlara ilişkin teorik bilgiler aktarmış, ardından turizm ve otelcilik sektöründe faaliyet gösteren bir firma için değerleme uygulaması yapmıştır. Söz konusu uygulamada indirgenmiş nakit akışları ve net aktif değeri yaklaşımları kullanılmıştır. Her durumun kendi koşullarında uygun bir değerleme yaklaşımıyla değerlendirilmesi için makul fiyatın ortaya konması gerekliliğine dikkat çekilen çalışmada, firma değerlemesi yaklaşımlarının oldukça gerçekçi sonuçlar verdiğine de vurgu yapılarak, elde edilen sonucun hem varlıkların güncel değerini göstermesi hem de gelecekte elde edilecek nakit akışlarının 1skonto edilmesi açısından uygun bir yöntem olduğu da ifade edilmiştir.

Hartwellab, C. A. ve Malinowskac (2019) ise kurumsal çevrenin firma değerlemesi üzerindeki etkileri üzerine yoğunlaşmışlardır ve konuyla ilgili araştırmaların, resmi kurumlar ve özellikle yasal çerçeveler üzerinde odaklandığına dikkat çekmişlerdir. Ayrıca, resmi kurumlardaki değişikliklerin, bir ülkede iş yapmanın yolunu belirleyen derinden kökleşmiş sosyo-ekonomik süreçler üzerinde hiçbir etkisi olmayabileceğini, bu tür bir durumda gayrı resmi kurumların firmalar için çok daha önemli bir rol oynayabileceğini de ifade etmişlerdir. Söz konusu makalede mülkiyet hakları örnek olarak kullanılmış ve resmi ve gayri resmi kurumsal değişikliklerin Polonyalı firmaların pazar büyüme potansiyeli üzerindeki etkisi 
modellenmiştir. Çalışma sonucunda, istikrarsız bir kurumsal ortamdaki firma değerlemesinin, şirkete özgü niteliklerden daha çok gayrı resmi mülkiyet haklarındaki gelişmeler ve firma dışındaki diğer faktörlerden kaynaklandığı sonucuna varılmıştır.

Nguyen, P., Rahman, N. ve Zhao, R. (2018) da yaygın olarak karşılaşılabilen üç CEO özelliğinin firma değerlemesi üzerindeki etkilerini incelemişlerdir. Bu amaçla, 2001-2011 dönemine ilişkin, Avustralya şirketleri içinden 2.702 gözlem örneğini kullanmışlardır. Araştırma sonuçlarına göre, CEO yaşının düşük şirket değerlemesi ile ilişkili olduğu tespit edilmiştir. Ayrıca, CEO görev süresinin de benzer şekilde daha düşük değerlemeyle ilişkili olduğu, ancak yüksek büyüme fırsatlarına sahip firmalar için ilişkinin daha da anlamlı olduğu belirtilmiştir. Buna karşılık, CEO dualitesinin ise sadece yüksek büyüme firsatlarına sahip firmalar için faydalı olduğu bulunmuştur. Genel olarak, çalışma CEO özellikleri ile firma değerlemesi arasındaki koşullu ilişkiyi vurgulamaktadır.

Gaio, C. ve Raposo, C. (2010 ) ise firma değerlemesi ve kazanç kalitesi arasındaki ilişkiyi araştırmak için 38 ülkedeki 7000'in üzerinde firmayı inceledikleri bir çalışma yapmışlardır. Firma değerlemesi ile toplam kazanç kalite ölçütü arasında yedi kazanç niteliğine bakarak pozitif ve anlamlı bir ilişki bulmuşlardır. Bu ilişki özellikle daha büyük yatırım firsatları olan ve dış finansmana ihtiyaç duyan firmalar ile düşük yatırımcıyı koruyan ülkelerdeki firmalar için daha güçlüdür. Böylece, şirketler, özellikle küresel sermaye piyasalarına erişmeleri gerektiğinde, daha yüksek kazanç kalite standartları benimseyerek, zayıf bir yasal ortamı telafi edebilmektedirler. Çalışma sonucunda elde edilen bulgular, daha yüksek kazanç kalitesine sahip firmaların borsalarda daha fazla değerlendiğini ve yatırımcıların düşük kaliteli kazançlarla ilgili bilgi riski için bir prim talep ettiği fikrini destekler niteliktedir.

\section{UYGULAMA VE BULGULAR}

Bu çalışma kapsamında, uluslararası hava yolu şirketi olarak faaliyet gösteren THY'nin indirgenmiş serbest nakit akım ve benzer şirket yöntemleri uygulanarak şirket değeri hesaplanmış ve elde edilen sonuçlar al-sat-tut kararı açısından yorumlanmıştır. Uygulanan metotlara ilişkin detaylar ayrı başlıklar halinde verilmiştir. Ayrıca ilgili firmanın 2015, 2016, 2017 ve 2018 yıllarına ait SNA, Ciro ve Kâr değerleri uygulama öncesi öngörü oluşturması için ve elde edilen sonuç değerleri ise daha sonra detaylı olarak açıklanmak ve yorumlanmak üzere aşağıda özet tablo halinde verilmiştir.

Tablo1. THY 2015, 2016, 2017, 2018 verileri

\begin{tabular}{|c|r|r|r|}
\hline Dönem & Serbest Nakit Akışı & $\begin{array}{c}\text { Gelir } \\
\text { (Revenue) }\end{array}$ & $\begin{array}{c}\text { Net Gelir } \\
\text { (Net Income) }\end{array}$ \\
\hline $12 / 31 / 2015$ & $2.178,30$ & $28.752,00$ & $2.993,00$ \\
\hline $12 / 31 / 2016$ & $-14.938,00$ & $29.468,00$ & $-47,00$ \\
\hline $12 / 31 / 2017$ & $6.332,92$ & $39.779,00$ & 639,00 \\
\hline $09 / 30 / 2018$ & $10.388,58$ & $56.814,00$ & $3.899,00$ \\
\hline Tahmini SNA & $6.299,93$ \\
\hline AOSM & \multicolumn{3}{|c|}{$24,03 \%$} \\
\hline Borçlanma Maliyeti & $26,35 \%$ \\
\hline Özsermaye Maliyeti & $31,12 \%$ \\
\hline Şirket Değeri & \multicolumn{3}{|c|}{$104.474,44$ milyon } \\
\hline Özsermaye & \multicolumn{3}{|c|}{$22,250,00$ milyon } \\
\hline Hedef Fiyat & \multicolumn{3}{|c}{} \\
\hline
\end{tabular}

\section{1. İndirgenmiş Serbest Nakim Akım Yöntemi ile Şirket Değerinin Hesaplanması:}

Uluslararası marka değerlendirme kuruluşu Brand Finance'in araştırmasına göre, "Türkiye'nin en değerli markası" seçilen ${ }^{1}$ THY'nin serbest nakit akım yöntemi ile hesaplaması yapılırken sırasıyla ilk olarak, -sonraki aşamalarda da girdi olarak kullanılacağı için- ağırlıklı ortalama sermaye maliyeti, ikinci olarak

\footnotetext{
${ }^{1} \mathrm{https}$ ://www.bloomberght.com > sayfasından elde edilmiş bir bilgidir.
} 
büyüme oranı ve son olarak da indirgenmiş serbest nakit akım öngörüsü belirlenerek şirket değeri hesaplanacaktır.

\subsubsection{Ağırlıklı Ortalama Sermaye Maliyetinin (AOSM) Hesaplanması:}

Bu ilk aşamada, "1skonto oranı" olarak şirket değeri hesaplamasında kullanılmak üzere ağırlıklı ortalama sermaye maliyeti hesaplanacaktır. Bu amaçla öncelikle aşağıdaki formül uyarınca, hesaplamada kullanılacak değişkenler belirlenecektir.

$$
\begin{aligned}
& \operatorname{AOSM}(\mathrm{R})=\quad \text { Öz sermaye Oranı*Öz sermaye Maliyeti + } \\
& \text { Borçlanma Oranı*Borçlanma Maliyeti*(1-Vergi Oranı) }
\end{aligned}
$$
verilmiştir.

İlgili formülden hareketle sırasıyla gerekli değişkenlerin hesaplanma detayları ve sonuçları aşağıda

\section{Öz sermaye Orant:}

Bu değişken için;

$$
\text { Öz sermaye Oranı = Toplam Öz sermaye/ (Toplam Öz sermaye }+ \text { Toplam Borçlar) }
$$

formülünden hareketle; Bloomberg'den ilgili firma için elde edilen "Balance Sheet - Standardized" sayfasındaki bilanço esas alınarak en güncel "Total Equity" ve "Total Liabilities \& Equity" gerçekleşmeleri olan 2017 yılsonu değerleri kullanılarak aşağıdaki sonuç elde edilmiştir.

Tablo2. Özsermaye Oranı

\begin{tabular}{|l|l|l|l|}
\hline $\begin{array}{l}\text { Özsermaye Maliyeti }= \\
\text { (Risksiz faiz oranı) }+ \text { (Beta) x (Piyasa risk primi) }\end{array}$ & $=$ & $31,12 \%$ & \\
\hline Risksiz Faiz Oranı & $=$ & $21,35 \%$ & (Bloomberg'den elde edilmiştir.Bknz.- Ek1) \\
\hline Beta & $=$ & 0,977 & (Bloomberg'den elde edilmiștir.Bknz.- Ek2) \\
\hline Piyasa Risk Primi (Rm-Rf) & $=$ & 0,10 & \\
\hline
\end{tabular}

Tablo3. Özsermaye Maliyeti

\begin{tabular}{|l|l|r|}
\hline $\begin{array}{c}\text { Öz sermaye Oranı => Toplam Öz sermaye } / \\
\text { (Toplam Öz sermaye + Toplam Borçlar) }\end{array}$ & $=$ & $\mathbf{2 9 , 3 8 \%}$ \\
\hline Toplam Öz sermaye & $=$ & $20.171,00$ \\
\hline Toplam Öz sermaye + Toplam Borçlar & $=$ & $68.647,00$ \\
\hline
\end{tabular}

\section{$\ddot{O} z$ sermaye Maliyeti:}

Bu değişken için;

Öz sermaye Maliyeti $=($ Risksiz faiz oran 1$)+($ Beta $) \times($ Piyasa risk primi $)$

şeklindeki öz sermaye maliyeti formülünden hareketle; sırasıyla risksiz faiz oranı, beta ve piyasa risk primi değişkenleri aşağıdaki şekilde elde edilerek formülde yerine konmuştur. kullanılmıştır.

Risksiz Faiz Oranı değişkeni için; güncel DIBS faiz oranı Bloomberg'deki değer esas alınarak 
Beta değişkeni için; yine Bloomberg'de ilgili firma için hesaplanan beta değeri kullanılmıştır. $\mathrm{Bu}$ değerin 1'den küçük olması, THY'nin piyasadan daha az duyarlı olduğuna işaret etmektedir.

Piyasa risk primi değişkeni içinse; literatürde belirlenen genel kullanım oranlarının \%6-\%10 aralığında olduğu varsayımıyla ve ülke ekonomisinin içinden geçmekte olduğu zorlu dönem de gözetilerek üst değer esas alınmıştır. Bu değişken için sektöre ilişkin güncel finansal veriler de incelenmiş; ancak yönlendirici bir sonuca ulaşılamamıştır.

\section{Borçlanma Oranı:}

Bu değişken için;

Borçlanma Oranı $=$ Toplam Borç/ (Toplam Öz sermaye + Toplam Borçlar)

formülünden hareketle; Bloomberg'den ilgili firma için elde edilen "Balance Sheet - Standardized" sayfasındaki bilanço esas alınarak en güncel "Total Liabilities" ve "Total Liabilities \& Equity" gerçekleşmeleri olan 2017 yılsonu değerleri kullanılarak aşağıdaki sonuç elde edilmiştir.

Tablo4. Borçlanma Oranı

\begin{tabular}{|l|l|r|}
\hline $\begin{array}{c}\text { Borçlanma Oranı => Toplam Borç / } \\
\text { (Toplam Özsermaye + Toplam Borçlar) }\end{array}$ & $=$ & $\mathbf{7 0 , 6 2 \%}$ \\
\hline Toplam Borçlanma & $=$ & $48.476,00$ \\
\hline Toplam Özsermaye + Toplam Borçlar & $=$ & $68.647,00$ \\
\hline
\end{tabular}

Borçlanma Maliyeti:

Bu değişken için;

Borçlanma Maliyeti =Beklenen Enflasyon+Reel faiz + Firma risk primi

formülünden hareketle; sirasıyla (Beklenen Enflasyon+Reel faiz) toplamı yerine risksiz faiz oranı ve firma risk primi değişkenleri aşağıdaki şekilde elde edilerek formülde yerine konmuştur.

Risksiz Faiz Oranı değişkeni için; sermaye maliyetinde olduğu güncel DIBS faiz oranı Bloomberg'deki değer esas alınarak kullanılmıştır.

Firma risk primi değişkeni içinse; firmanın piyasadan daha az duyarlı olması, geçmiş yıllarda en değerli marka seçilmiş olması ve büyüme oranlarının da pozitif eğilimde olması nedeniyle; piyasa risk priminden daha düşük bir değer belirlenmiştir. Bu değişken için firmaya ilişkin güncel finansal veriler de incelenmiş; giriş bölümünde ve eklerde de detayı verildiği gibi firmaya ilişkin olumlu bildirimler de gözetilmiştir.

Tablo5. Borçlanma Maliyeti

\begin{tabular}{|l|r|r|l|}
\hline \multicolumn{1}{|c|}{ Borçlanma Maliyeti =Beklenen } & & \\
Enflasyon+Reel faiz + Firma risk primi & $=$ & $\mathbf{2 6 , 3 5 \%}$ & \\
\hline $\begin{array}{l}\text { Risksiz Faiz Oranı (Beklenen } \\
\text { Enflasyon+Reel Faiz) }\end{array}$ & & $21,35 \%$ & (Bloomberg'den elde edilmiştir.Bknz.- Ek1) \\
\hline Firma Risk Primi & & 0,05 & \\
\hline
\end{tabular}

AOSM formülünde yer alan vergi oranı da güncel veriler doğrultusunda formülde yerine koyulduğunda; aşağıdaki sonuç elde edilmiştir. 
Tablo6. Ağırlıklı Ortalama Sermaye Maliyeti

\begin{tabular}{|l|c|r|}
\hline \multicolumn{1}{|c|}{$\begin{array}{c}\text { Ăğırlıkı Ortalama Sermaye Maliyeti(R)= } \\
\text { Özsermaye Oranı* Özsermaye Maliyeti }+\end{array}$} & \\
Borçlanma Oranı*Borçlanma Maliyeti*(1-Vergi Oranı) & $=$ & $\mathbf{2 4 , 0 3 \%}$ \\
\hline Özsermaye Oranı & $=$ & $29,38 \%$ \\
\hline Özsermaye Maliyeti & $=$ & $31,12 \%$ \\
\hline Borçlanma Oranı & $=$ & $70,62 \%$ \\
\hline Borçlanma Maliyeti & $=$ & $26,35 \%$ \\
\hline Vergi Oranı & $=$ & $20 \%$ \\
\hline
\end{tabular}

\subsubsection{Büyüme Oranının Hesaplanması:}

İndirgenmiş nakit akım yönteminde girdi olarak kullanılacak bir başka değişken olan büyüme oranı içinse finansal uygulamalarda yaygın bir yöntem olarak kullanılan "ciro" daki değiş̧im oranı esas alınmıştır. Bu amaçla; son 4 yılın (2016 yılı hariç; gerekçesi 3.1.3 adımında açıklanmıştır) Bloomberg'den elde edilen "income adjusted" sayfasındaki "revenue" , "gross profit" ve "EBITDA" değerine göre büyüme oranlarının ortalaması alınarak üç farklı oran bulunmuştur. Ancak elde edilen büyüme oranlarından, artan yakıt fiyatları ${ }^{2}$ (\%26) ve ülkenin içinden geçtiği süreç nedeniyle küçük olanı alınmıştır.

Tablo7. Büyüme Oranı

\begin{tabular}{|l|l|l|l|l|l|l|l|l|}
\hline Gross Profit, Adj & $2.009,3$ & $3.045,1$ & $3.472,1$ & $4.429,0$ & $5.793,0$ & $3.417,0$ & $7.836,0$ & $12.800,0$ \\
\hline Margin \% & 17,0 & 20,6 & 18,5 & 18,3 & 20,1 & 11,6 & 19,7 & 22,5 \\
\hline EBITDA, Adj & $1.258,0$ & $2.213,2$ & $2.393,3$ & $3.108,0$ & $4.745,0$ & $2.675,0$ & $6.858,0$ & $10.447,0$ \\
\hline Margin \% & 10,6 & 15,0 & 12,7 & 12,9 & 16,5 & 9,1 & 17,2 & 18,4 \\
\hline
\end{tabular}

\begin{tabular}{|c|c|c|c|c|c|}
\hline In Millions of TRY & FY 2015 & FY 2016 & FY 2017 & Current/LTM & $\begin{array}{c}\text { Ortalama } \\
\text { Büyüme } \\
\text { Oranı } \\
\text { (\%) }\end{array}$ \\
\hline 12 Months Ending & $12 / 31 / 2015$ & $12 / 31 / 2016$ & $12 / 31 / 2017$ & $09 / 30 / 2018$ & \\
\hline Revenue, Adj & $28.752,0$ & $29.468,0$ & $39.779,0$ & $56.814,0$ & \\
\hline Growth \%, YoY & 19,0 & 2,5 & 35,0 & 55,1 & $\% 36,37$ \\
\hline Gross Profit, Adj & $5.793,0$ & $3.417,0$ & $7.836,0$ & $12.800,0$ & \\
\hline Margin \% & 20,1 & 11,6 & 19,7 & 22,5 & $\% 20,79$ \\
\hline EBITDA, Adj & $4.745,0$ & $2.675,0$ & $6.858,0$ & $10.447,0$ & \\
\hline Margin \% & 16,5 & 9,1 & 17,2 & 18,4 & $\mathbf{\% 1 7 , 3 8}$ \\
\hline
\end{tabular}

\subsection{3. İndirgenmiş Nakit Akımlarının Hesaplanması:}

$\mathrm{Bu}$ aşamada ise öncelikle aşağıda uygulama mantığı (Şekil.1) verilen indirgenmiş nakit akımlar yöntemi çerçevesinde; geçmiş performans verileri de değerlendirilerek gelecek tahminlemesi yapılacaktır. Çalı̧̧ma için öncelikle bir tahmini gelecek SNA öngörüsü yapılacak sonrasında ise aşağıda verilen indirgenmiş nakit akım formülü (6) uygulanacaktır.

Bu amaçla ilk olarak Bloomberg HT'den elde edilen "cash flow tablosu" incelenmiş ve gelecek dönem serbest nakit akım öngörüsü yapılmıştır. THY'nin "cash flow to firm" değerleri incelendiğinde 2016 yılında olağandışı bir sapma ve negatife düşme durumu göze çarpmaktadır. Bu dönemde, önceki dönemlere oranla operasyonel yatırımların azalması da belirtilen durumu desteklemektedir. Konuyla ilgili firmaya ilişkin finansal analiz bulguları ve faaliyet raporları da incelendiğinde 2016 yılında firmanın yaşadığı durum şu şekilde belirtilmiştir:

"2016 yılı hem havacılık sektörü genelinde hem de Türk Hava Yolları özelinde birçok açıdan zorlu bir sene olmuştur. Hava yollarının en büyük maliyet kalemi olan akaryakıt fiyatlarında yaşanan \%20'lere varan düşüs, sektörde ortalama \%6'lara varan kapasite artışını ve beraberinde artan rekabet

2 Ek.5’te belirtilen Uluslararası Hava Taşımacıları Birliği'nin açıklaması esas alınmıştır. 
koşulların getirmiştir. Talep ve hava yolları finansalları üzerinde etkili olan bir diğer faktör de kurlarda yaşanan dalgalanmalar olmuştur. Özellikle gelişen ülke para birimlerinin USD karşlsındaki değer kaybı sektörün fiyatlama ve planlama konusunda zorlanmasına sebep olmuştur. Global etkilerin yanı sıra 2016 yılında ülkemizde gerçekleşen olumsuz olayların da etkisiyle Türk Hava Yolları'nın toplam gelirleri geçen yıla göre \%6,9 oranında gerilemiştir." 3

Dolayısıyla; tahminleme sürecinde bu tür genele yayılmayan oynaklıkların geleceğe yansımayacağı varsayımıyla ve benzer şekilde FX'lerle ilgili artma/azalmalar ile olağandışı kar ve zararların uzun dönemde birbirinin etkisini sıfırlayacağı öngörüsüyle; çalışma kapsamında istikrarlı seyrettiği düşünülen güncel üç döneme ait gerçekleşme verileri (2015, 2017 yılı ile 2018. Eylül verileri olmak üzere) esas alınmıştır. Ayrıca, zamanın taşıdığı değişkenliğin ve belirsizliğin doğal sonucu olarak öngörü süresinin çok uzun seçilmemesi de literatürde önerilen bir kabul olduğundan bu varsayımı destekler niteliktedir4. Şekill'de özetlenen çerçeve esas alınarak geçmiş performans verisi olarak, son iki yıl belirlendikten sonra ikinci aşamada ise "artık yıl" yaklaşımıyla; yine geçmiş performans verilerinden bir gelecek SNA tahminlemesi yapılmış ve elde edilen üç dönem için bulunan veriler 6 no'lu formülde yerine konmuştur. Ancak bulunan değer mevcut ekonomik ortam için yüksek olduğundan, bu formülden elde edilen değer yerine tahmini SNA değeri kullanılmıştır.

Şekil1. İndirgenmiş Nakit Akımlar Bileşenleri

\section{iNAA Hesaplanan Değer Bileşenleri}

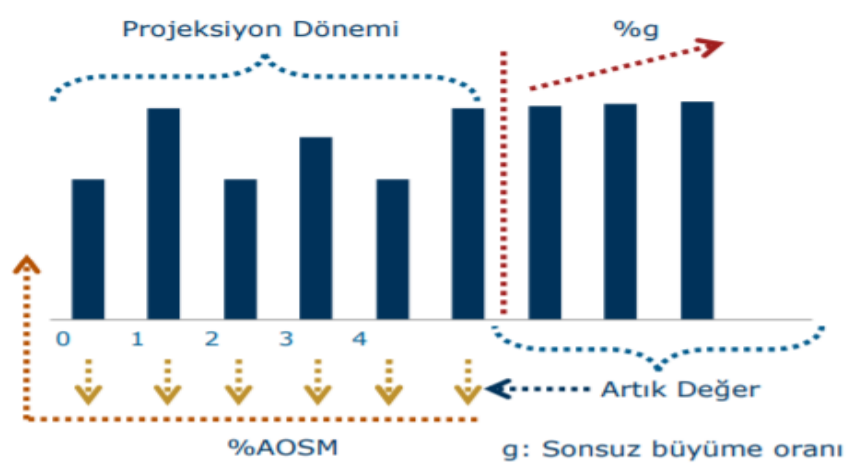

$\mathrm{SNA}=$ Vergi ve faiz öncesi kar + Amortisman - Vergiler - Planlanan yatırım harcamaları

Böylece firmanın toplam değeri, $V_{0}$, șöyle ifade edilebilir:

$$
V_{0}=\sum_{t=1}^{m} \frac{S N A_{t}}{(1+r)^{t}}
$$

$P_{0=}$ Tahmini Nakit Akım(SNA) /(AOSM (R)-Büyüme Oranı $\left.(g)\right)$

Gelecek döneme ilişkin SNA öngörüsü yapılırken; büyüme oranına benzer şekilde firmanın son dört "cash flow to firm" gerçekleşmelerinin -2016 yılı dışlanarak- ortalaması alınarak üçüncü dönem SNA değeri belirlenmiştir. Bu üç verinin formüle edilmesinden sonra elde edilen indirgenmiş nakit akım değeri ise, 7 no'lu formülde yerine koyularak şirket değeri belirlenmiştir. Elde edilen şirket değeri ise firmanın hisse adedine

3 Türk Hava Yolları |2016 Yıllık Raporu

4 İndirgenmiş Nakit Akımları Yöntemine Göre Firma Değerleme Ve Enerji Sektöründe Bir Uygulama, Ahmet Cingöz, Doktora Tezi, 2014 
bölünerek; hisse değeri hesaplanmıştır. Ayrıca, bu değerin öz sermayeye karşı1ık düşen payı için de, elde edilen değer öz sermaye oranı ile çarpılarak; nihai sonuca ulaşı1mıştır.

Buna göre elde edilen değer; Bloomberg'de yayınlanan güncel hisse değerine kıyasla büyük olduğundan; çalışma sonucunda THY için "AL" kararı çıkmıştır. Firmanın güncel marka değerine ve piyasadaki konumuna bakıldığında; elde edilen sonucun mevcut konjoktürle uyumlu olduğu görülmektedir. Ayrıca, elde edilen sonuç İş İnvest ${ }^{5}$ ve Şeker İnvest ${ }^{6}$ yatırım firmalarının finansal analiz raporlarında yer alan değerlerle de tutarlıdır. edilmiştir

Anlatılan bu varsayımlar ve uygulamalar sonucunda aşağıdaki tablolarda özetlenen nihai değerler elde

Tablo8. Şirket Değeri

\begin{tabular}{|l|l|l|l|}
\hline \multicolumn{1}{|c|}{ HESAPLANAN DEĞER } & & SONUÇ & \multicolumn{1}{|c|}{ AÇIKLAMA } \\
\hline Gelecek Dönem SNA Tahmini & $=$ & $6.299,93$ & $\begin{array}{l}\text { Son 4 yılın "Cash Flow to Firm" değerlerinin ortalamaları } \\
\text { alınark belirlenmiştir (2016 y1l raporda belirtilen } \\
\text { gerekçe nedeniyle dişlanmıştır). }\end{array}$ \\
\hline Şirket Değeri (P0) & $=$ & 104.474 & \begin{tabular}{l} 
Tahmini SNA/(AOSM(R)-Büyüme Oranı(g)) \\
\hline Büyüme Oranı Tahmini(g) (\%)
\end{tabular} \\
\hline
\end{tabular}

Tablo9. AL-SAT-TUT Kararı

\begin{tabular}{|l|l|r|l|}
\hline Hisse Sayısı & $=$ & $\mathbf{1 . 3 8 0 . 0 0 0 . 0 0 0 , 0 0}$ & Özz sermaye değeri alınmıștır. \\
\hline Hisse Değeri & $=$ & $\mathbf{7 5 , 7 1}$ & \\
\hline Hisse Değeri - Özsermaye Oranına göre & $=$ & $\mathbf{2 2 , 2 5}$ & $\begin{array}{l}\text { Hisse değerinin özsermayeye düşen } \\
\text { payı belirlenmiştir. }\end{array}$ \\
\hline Güncel Hisse Fiyatı & $=$ & $\mathbf{1 5 , 2 5}$ & $\underline{\underline{\text { Bloomberg'den elde }}}$ \\
\hline Al-Sat-Tut Kararı & $=$ & AL & \\
\hline
\end{tabular}

\subsection{Benzer Şirket Yöntemi ile Şirket Değerinin Hesaplanması:}

Bu yöntemde ise, ilk aşamada THY'nin faaliyet sektörü ve ölçeği göz önüne alınarak borsaya kote olmuş muadil şirketler belirlenmiştir. Bu şirketler aşağıda detayı verildiği gibi yurtdışı kökenli hava yolu şirketleridir. Türkiye'de yer alan rakip havayolları şirketleri hem THY ile ölçek farkı içermesi hem de THY'nin ülkede alanında birinci olarak dış pazar payını artırmaya dönük hedeflerinin olması nedeniyle çalışma kapsamına alınmamıştır.

Bu yöntemle yapılan değerlendirmede; ilgili firmaların "P/E", "EV/EBITDA" ve "Price/Book Value" katsayıları esas alınmış ve minimum, medyan ve ortalama değerler incelenmiştir.

Öncelikle "P/E" katsayısı için; muadil şirketlerin medyan değeri alınarak firmaya ilişkin Bloomberg "incomeadjusted" sayfasında yer alan "Basic-EPS değeri ile çarpılmış ve şirket değeri aşağıdaki özet tabloda verildiği gibi hesaplanmıştır. Buna göre P/E’ye göre hisse değeri; Bloomberg'de yayınlanan güncel hisse değerine kıyasla büyük olduğundan; çalışma sonucunda THY için “AL” kararı çıkmıştır ve bu sonuç indirgenmiş nakit akım yöntemiyle tutarlıdır.

5 Ek.6'da özet analiz sonuçları paylaşılmıştır

6 Ek.7'de özet analiz sonuçları paylaşılmıştır. 
"EV/EBITDA" katsayısı da yatırım yapılmak istenen sektörde satın alınmak istenen şirketin, piyasadaki şirketlere göre değerinin tespit edilmesinde sıklıkla kullanılır. Bu değer her şirketin kendi sektöründeki ortalamasıyla karşılaştırılarak değerlendirilir. Şirket satın almalarında tercih edilen oran, sektör ortalamalarından daha düşük bir EV/EBITDA oranı olmaktadır. Bu anlamda; THY'nin EV/EBITDA değerinin rakiplerinin üzerinde olduğu görülmektedir.

"Price/Book Value" katsayısının düşük olması, firmanın piyasada olması gerekenden daha düşük değerlendiği konusunda ipucu verir. Düşük "P/B” değerine sahip işletmelere yatırım yapılması durumunda yüksek getiri elde edilmesi beklenebilir; ancak aynı zamanda bu değerlemeye neden olabilecek bir sorun olduğuna da işaret edebilir. Bu anlamda; THY'nin P/B değerinin 1'den küçük olması nedeniyle analiz kapsamında değerlendirme dışı bırakılması uygun bulunmuştur.

Tablo10. AL-SAT-TUT Kararı

\begin{tabular}{|l|r|r|r|}
\hline \multicolumn{1}{|c|}{ Name } & Est P/E Current Yr & \multicolumn{1}{|c|}{ EV/EBITDA } & \multicolumn{1}{c|}{ PrIce / Book Value } \\
\hline TURK HAVA YOLLARI AO & & & 0,574387947 \\
\hline AIR FRANCE-KLM & 4,898811436 & 6,168057906 & 1,250596695 \\
\hline INTL CONSOLIDATED AIRLINE-DI & 6,67877095 & 4,65533517 & 1,784599779 \\
\hline SAS AB & 5,755660362 & 2,765234672 & 0,962645118 \\
\hline FINNAIR OYJ & 7,453287197 & 2,498060804 & 0,822818587 \\
\hline DEUTSCHE LUFTHANSA-REG & 8,965087282 & 2,11632682 & $\mathbf{1 , 7 8}$ \\
\hline & 4,645138396 & 2,41154419 & $\mathbf{0 , 5 7}$ \\
\hline Max & & & $\mathbf{1 , 2 3}$ \\
\hline MIn & $\mathbf{8 , 9 7}$ & $\mathbf{4 , 6 6}$ & $\mathbf{1 , 2 5}$ \\
\hline Ort & $\mathbf{4 , 6 5}$ & $\mathbf{2 , 1 2}$ & \\
\hline Median & $\mathbf{6 , 7 0}$ & $\mathbf{2 , 8 9}$ & \\
\hline & $\mathbf{6 , 6 8}$ & $\mathbf{2 , 5 0}$ & \\
\hline & & & \\
\hline Basic EPS & $\mathbf{P} / \mathbf{E}$ 'ye göre & & \\
\hline Hisse Değeri & $\mathbf{2 , 8 3}$ & & \\
\hline
\end{tabular}

\section{SONUÇ, TARTIŞMA VE ÖNERÍLER:}

Sonuç olarak; indirgenmiş nakit akım yönteminin ve benzer şirket katsayıları içinde anlamlı sonuç verdiği düşünülen "P/E" "ye göre hisse değerinin sonuçları ve tutarlılığı; firmanın olumlu büyüme eğilimi ve marka değeri de gözetilerek çalışma sonucunda THY şirketi için “AL” kararının yatırımcı adına sağlıklı olduğu sonucuna varılmıştır.

Mevcut literatür ve uygulamalar 1şığında, her ne kadar firma değerlemelerinde kullanılan en sık yöntem olarak İndirgenmiş Nakit Akımları Yöntemi öne çıksa da; değerleme hatasının minimum düzeyde tutulması ve hissenin gerçek değerine ulaşılması için, değerlemede mümkün olduğunca çok yöntemin karşılaştırmalı olarak kullanılması önerilmektedir. Bu doğrultuda, THY için de iki farklı yöntem kullanılmış ve elde edilen sonuçların tutarlılı̆̆ kıyaslanmıştır. $\mathrm{Bu}$ da elde edilen sonuca olan güvenirliği artırmaktadır. Ayrıca, sağlıklı bir değerleme sonucuna ulaşmak için, değerleme için kullanılacak yöntemin seçimi ve uygulama sürecinde firmanın ve firmanın faaliyet gösterdiği sektörün spesifik özellikleri de dikkate alınmalıdır. 


\section{KAYNAKÇA}

Alkan, G. ve Demireli, E. (2007). Türkiye'de Kullanılan Bazı Şirket Değerleme Yöntemleri ve Bir Uygulama. Dokuz Eylül Üniversitesi Kurumsal Akademik Açık Arşivi, https://acikerisim.deu.edu.tr/xmlui/handle/20.500.12397/5468.

Avcı, P. ve Balc1, B. (2017). Firma Değerleme ve Uygulama. IV. IMCOFE / BARCELONA Young Scholars Union.

Aydın, Y. (2012). Firma Değerleme Yöntemleri. Kırklareli Üniversitesi İI.̇.B.F. Dergisi, 1(1), 87-110.

Bilir, H. ve Kulalı, İ. (2014). İndirgenmiş Nakit Akış ve Göreceli Değerleme Yöntemlerinin Karşılaştırılması. Siyaset, Ekonomi ve Yönetim Araştırmaları Dergisi, 2( 2).

Cingöz, A. (2014). İndirgenmiş Nakit Akımları Yöntemine Göre Firma Değerleme ve Enerji Sektöründe Bir Uygulama. Doktora Tezi, Selçuk Üniversitesi.

Çam, A. V. (2014). Politik Riskin Firma Değeri İle İlişkisi: İMKB’ye Kayıtlı Firmalar Üzerinde Bir Uygulama. Doğuş Üniversitesi Dergisi, 15 (1), 109-122.

Gaio, C. ve Raposo, C. (2010). Earnings Quality and Firm Valuation: International Evidence, https://doi.org/10.1111/j.1467-629X.2010.00362.x.

Gorbon, M. (2012). Şirket Değerleme Yöntemleri. TUYID. İş Yatırım.

Hartwellab, C. A. ve Malinowskac, A.P. (2019). Informal Institutions and Firm Valuation. Emerging Markets Review ,40.

Hatipoğlu, M. ve Yener, E. (2013). Firma Değerlemesinde İndirgenmiş Nakit Akımları Yöntemi: BIST Elektrik Endeksinde Bir Uygulama. Eskişehir Osmangazi Üniversitesi İIBF Dergisi, 8(3), 7 29.

Kayalı, C.A., Yereli, A. N. ve Ada, Ş. (2007). Entelektüel Katma Değer Katsayısı Yöntemi Kullanılarak Entelektüel Sermayenin Firma Değeri Üzerindeki Etkisinin Belirlenmesine Yönelik Bir Araştırma. Yönetim ve Ekonomi, 14 (1). Celal Bayar Üniversitesi İ.İ.B.F. Manisa.

Küçükkocaoğlu, G. ( Bilinmeyen Tarih ). Genel Kabul Görmüş Şirket Değerleme Yöntemleri. Erişim Adresi: http://www.baskent.edu.tr/ gurayk/finpazsirketdegerleme.doc.

Masun, M.A. (2017). Firma Değerlemesi Yaklaşımları ve Otelcilik İşletmesi Örneği. Marmara Üniversitesi İktisadi ve İdari Bilimler Dergisi, 39 (1), 213-222. DOI: 10.14780/muiibd.329927.

Nguyen, P., Rahman, N. ve Zhao, R. (2018). CEO Characteristics and Firm Valuation: A Quantile Regression Analysis. R. J Manag Gov, 22, 133. https://doi.org/10.1007/s10997-017-9383-7.

Yusufi Yılmaz, F. (2002). Firma Değerleme. YTU Kurumsal Açık Arşivi. http://dspace.yildiz.edu.tr/xmlui/handle/1/6879. 


\section{EKLER}

\section{Ek-1. Risksiz Faiz Oranı}

Kaynak: Bloomberg

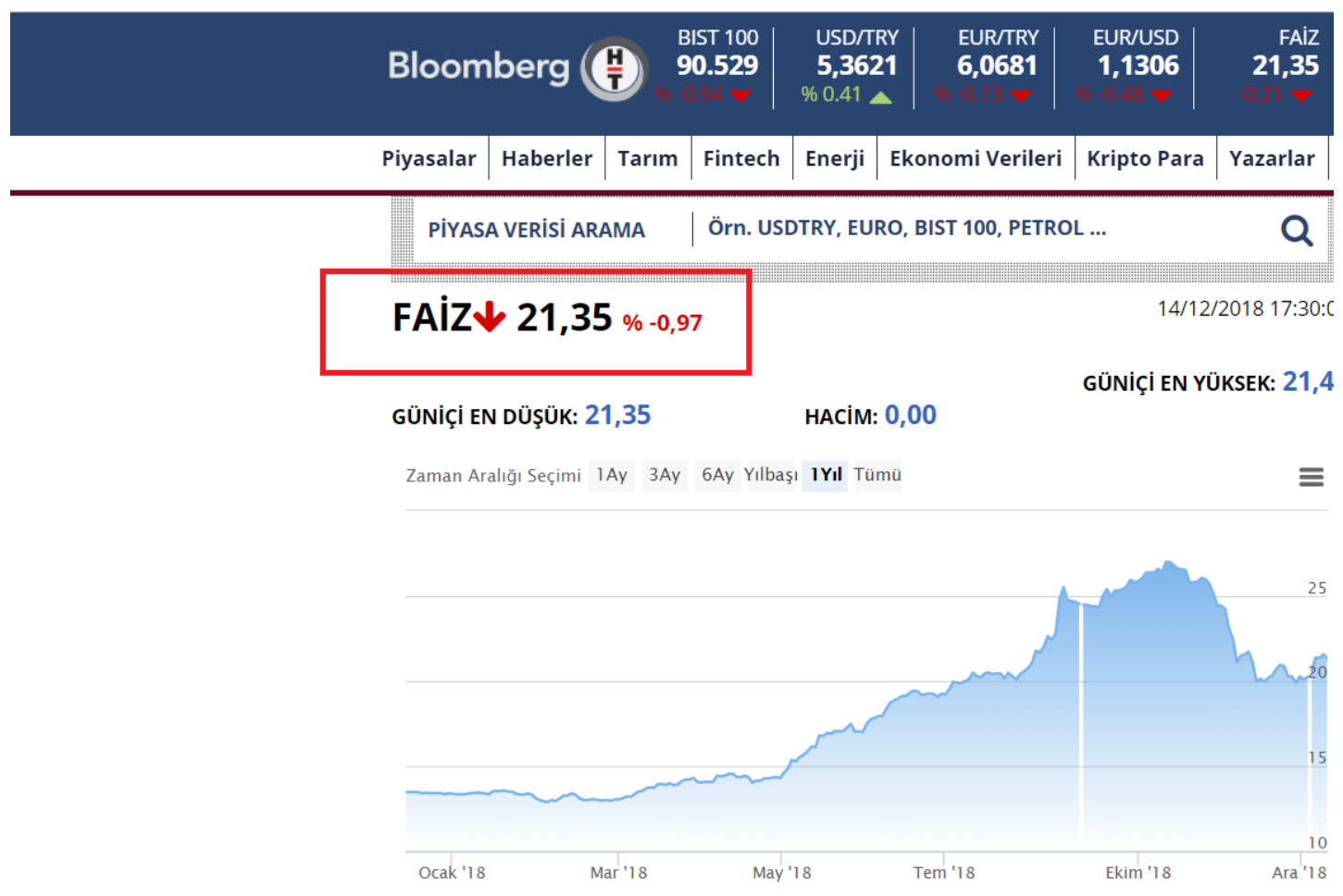

\section{Ek-2. THY Beta Katsayısı}

Kaynak: Bloomberg

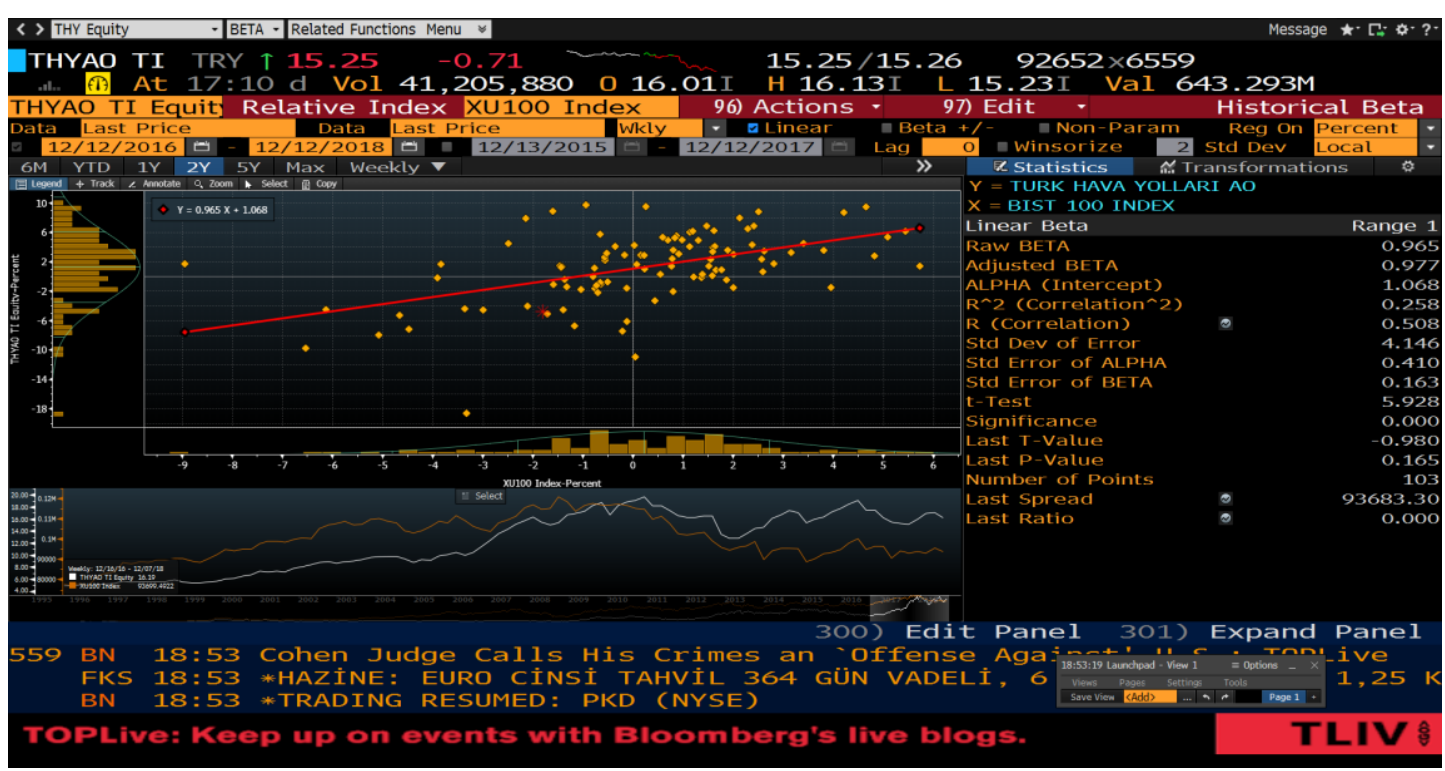




\section{Ek3- Güncel Hisse Değeri/Adedi}

Kaynak: Bloomberg

$\leftarrow \rightarrow \mathrm{C}$. https://www.bloomberght.com/borsa/hisse/turk-hava-yollar

\begin{tabular}{|c|c|c|c|c|c|c|c|c|}
\hline Bloon & iberg & & $\begin{array}{l}\text { BIST } 100 \\
90.529\end{array}$ & $\begin{array}{r}\text { USD/TR } \\
\mathbf{5 , 3 6 2} \\
\% 0.41\end{array}$ & $\begin{array}{l}\text { EUR/TRY } \\
\mathbf{6 , 0 6 8 1}\end{array}$ & $\begin{array}{r}\text { EUR/USD } \\
1,1306\end{array}$ & $\begin{array}{r}\text { FAiz } \\
21,35\end{array}$ & \\
\hline Piyasalar & Haberler & Tarım & Fintech & Enerji & Ekonomi Verileri & Kripto Para & Yazarlar & V \\
\hline
\end{tabular}

\begin{tabular}{l|l} 
PIYASA VERISI ARAMA & Örn. USDTRY, EURO, BIST 100, PETROL ...
\end{tabular}

\begin{tabular}{|l|}
\hline TURK HAVA \\
\hline ALIŞ: 14,95 \\
EN YÜKSEK: 15,34 \\
\hline HACIM (LOT): \\
36.539.444,00 \\
\hline
\end{tabular}

$14 / 12 / 2018$ 18:09:45

NET: -

HACIM (TL):

$545.910 .385,76$

\section{Ek-4: Çalışmada Atıf Yapılan Örnek Haber:}

Kaynak: https://www.bloomberght.com/haberler/haber/2133994-s-p-thy-nin-kredi-notunu-negatif-izlemedenHaberler / Türkiye Ekonomisi

\section{S\&P THY'nin kredi notunu negatif izlemeden çıkardı}

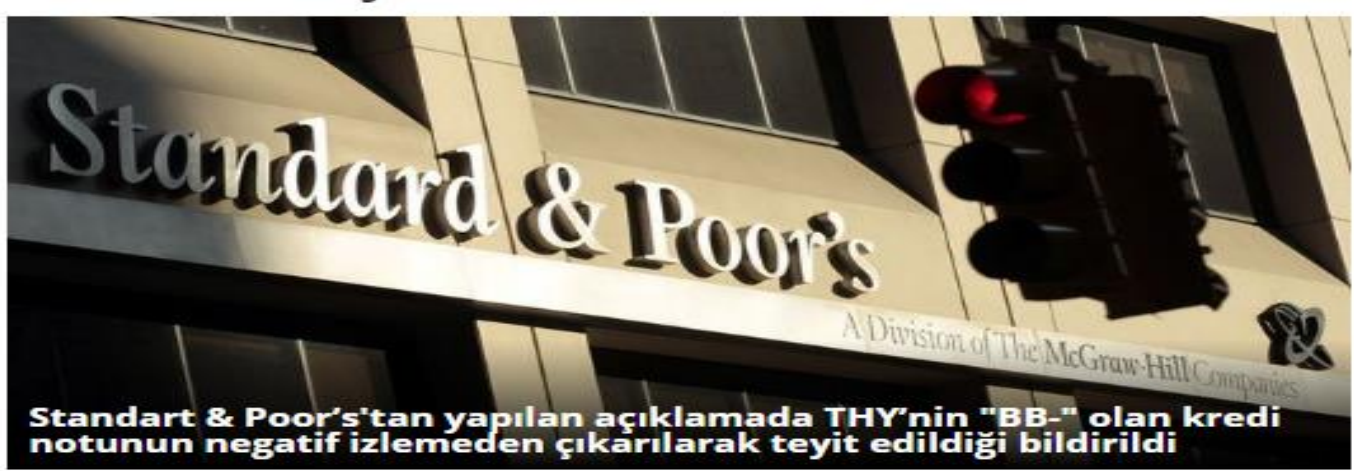

27 Haziran 2018 Carsamba, 16:54
Güncelleme: 27 Haziran 2018 Çarşamba,

Uluslararası kredi derecelendirme kuruluşu Standart \& Poor's (S\&P), Türk Hava Yollarinın (THY) kredi notunu negatif izlemeden çıkardığını duyurdu.

Kredi derecelendirme kuruluşundan yapılan açıklamada THY"nin "BB-" olan kredi notunun negatif izlemeden çıarılarak teyit edildiği, not görünümünün ise "durağan" olarak belirlendiğ bildirildi.

Açıklamada THY’nin zorlu 2016 yılından sonra, geçen yıl güçlü operasyonel sonuçlar elde ettiği vurgulandi.

Açıklamada, ön rezervasyonlar ve Türk turizmindeki iyileșmenin etkisiyle șirketin güçlü EBITDA (faiz, verg, amortisman öncesi kar) performansının 2018 yılında da devam etmesinin öngörüldügüu de bildirildi.

THY'nin bağımsız kredibilitesinin iyileştiğine vurgu yapılan açıklamada, durağan görünümün șirketin 2018 yılında güçlü kar elde edeceğine ilişkin beklentiyi yansıttığı kaydedildi.

cikardi

Açıklamada ayrıca önümüzdeki dönemde havayolları trafiğinde devam eden iyileșmenin artan yakıt fiyatları ve sermaye harcamalarını dengelemesinin beklendiği belirtildi. 


\section{Ek-5: Çalışmada Atıf Yapılan Örnek Haber:}

Kaynak: http://www.airturkhaber.com/haberler/jet-yakiti-fiyatlari-yukseliyor/

\section{Jet yakıtı fiyatları yükseliyor}

8 Temmuz 2018/

Uluslararası Hava Taşımacıları

Birliği, bu yıl jet yakıtı fiyatının 4'te

1'den fazla artacağını açıkladı.

TurizmGüncel'de yer alan habere göre, Uluslararası Hava

Taşımacıları Birliği (IATA) bu yıl jet yakıı fiyatlarının yüzde 26

oranında artacağını açıkladı.

Açıklamada ayrıca, ticaret

savaşlarının ve jeopolitik
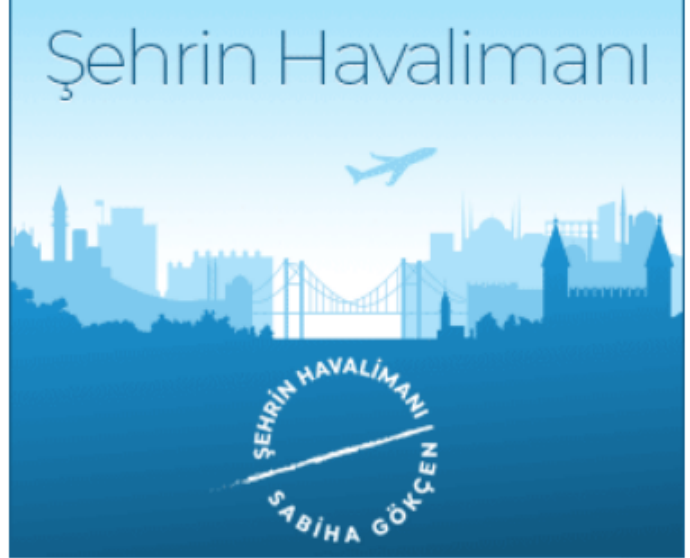

gerilimlerin de hava yolu

maliyetlerini attırdığına dikkat çekildi.

Hava yolu şirketlerinin geçen yıl 38.8 milyar dolar kar elde ettiğini ifade eden IATA Genel Müdürü Alexandre de Juniac, "Bu sağlam bir performans. Ancak hava yolu şirketlerinin şoklara karşı tamponu sadece 7.76 dolar. Bu, hava yolu şirketlerinin kişi başı elde ettiği karı ifade ediyor. Bu yıl hava yolu şirketlerinin yolcu başına elde ettiği kar yüzde 4.1 oranında azalacak."dedi. 
Ek-6: Çalışmada Atıf Yapılan İş İnvest Analiz Sonucu:

Kaynak: Işs Invest Analiz Raporu

Ticker

\begin{tabular}{|c|c|c|}
\hline Stock Data & $\mathrm{TL}(\boldsymbol{E})$ & US\$ \\
\hline Price & 14.65 & 2.70 \\
\hline Target Price & 22.80 & 4.07 \\
\hline Prev.TP & 26.30 & 4.02 \\
\hline Mcap (mn) & 20,217 & 3,731 \\
\hline Float Mcap (mn) & 10,106 & 1,865 \\
\hline Avg.Daily Volume (3M, mn) & 999.8 & 166.3 \\
\hline No. of Shares Outstanding $(\mathrm{mn})$ & & 1,380 \\
\hline Free Float $(\%)$ & & 50 \\
\hline Multiples & 2018E & $2019 \mathrm{E}$ \\
\hline 31.6 & 6.4 & 6.5 \\
\hline $\mathrm{P} / \mathrm{BV}$ & 0.7 & 0.7 \\
\hline EV/EBITDA & 6.2 & 5.2 \\
\hline
\end{tabular}

THYAO

Ek-7: Çalışmada Atıf Yapılan Şeker İnvest Analiz Sonucu:

Kaynak: Şeker Invest Analiz Raporu

OUTPERFORM

TP:TRY 20.45

Upside potential: $31 \%$ 